\title{
Antioxidant, antimicrobial and toxicological properties of Schinus molle L. essential oils
}

\author{
Maria do Rosário Martins ${ }^{\mathrm{a}, \mathrm{b}, *}$, Silvia Arantes $^{\mathrm{a}, \mathrm{b}}$, Fátima Candeias ${ }^{\mathrm{a}, \mathrm{b}}$, Maria Teresa Tinoco ${ }^{\mathrm{b}}$, \\ Júlio Cruz-Morais ${ }^{\text {b }}$
}

a Departamento de Química, Escola de Ciências e Tecnologia, Universidade de Évora, Rua Romão Ramalho 59, 7000-671 Évora, Portugal

b ICAAM-Instituto de Ciências Agrárias e Ambientais Mediterrânicas, Universidade de Évora, Ap. 94, 7002-554 Évora, Portugal

\section{A R T I C L E I N F O}

\section{Article history:}

Received 31 May 2013

Received in revised form

7 September 2013

Accepted 28 October 2013

Available online 11 November 2013

Keywords:

Schinus molle

American pepper

Essential oils

Biological activities

Toxicological studies

\begin{abstract}
A B S T R A C T
Ethnopharmacological relevance: Schinus molle L. has been used in folk medicine as antibacterial, antiviral, topical antiseptic, antifungal, antioxidant, anti-inflammatory, anti-tumoural as well as antispasmodic and analgesic; however, there are few studies of pharmacological and toxicological properties of Schinus molle essential oils. The aim of this study was to evaluate the antioxidant and antimicrobial activities of Schinus molle leaf and fruit essential oils, correlated with their chemical composition and evaluate their acute toxicity.

Materials and methods: The chemical composition of Schinus molle leaf and fruit essential oils were evaluated by GC-FID and GC-MS. Antioxidant properties were determined using the 2,2-diphenyl-1picryl-hydrazyl (DPPH) free radical and $\beta$-carotene/linoleic acid methods. Antimicrobial properties were evaluated by the agar disc diffusion method and minimal inhibitory concentration assay. Toxicity in Artemia salina and acute toxicity with behavioural screening in mice were evaluated.

Results: The dominant compounds found in leaf and fruit essential oils (EOs) were monoterpene hydrocarbons, namely $\alpha$-phellandrene, $\beta$-phellandrene, $\beta$-myrcene, limonene and $\alpha$-pinene. EOs showed low scavenging antioxidant activity by the DPPH free radical method and a higher activity by the $\beta$ carotene/linoleic acid method. Antimicrobial activity of EOs was observed for Gram+, Grampathogenic bacteria and food spoilage fungi. EOs showed totoxicity for Artemia salina and lower toxicity in Swiss mice.

Conclusions: The result showed that EOs of leaves and fruits of Schinus molle demonstrated antioxidant and antimicrobial properties, suggesting their potential use in food or pharmaceutical industries.
\end{abstract}

(c) 2013 Elsevier Ireland Ltd. All rights reserved.

\section{Introduction}

Essential oils (EOs) and extracts of aromatic plants have been recognised for many years as a great source of pharmaceutical agents and food additives (Joy et al., 2007). Their antioxidant capacity for acting in metabolic response to the endogenous production of free radicals and other oxidant species has been demonstrated (Scalbert et al., 2005; Pintore et al., 2009; Wei and Shibamoto, 2010). Furthermore, EOs have shown important in vitro antimicrobial properties against pathogens and foodborne agents causing diseases (Hammer et al., 1999). Schinus molle L., commonly known as pink pepper or American pepper is a tree belonging to the Anacardiaceae family which is native to subtropical regions of South America. It was introduced and

\footnotetext{
* Corresponding author at: Universidade de Évora, Departamento de Química, Escola de Ciências e Tecnologia, Rua Romão Ramalho 59, 7000-671 Évora, Portugal. Tel.: + 351266745311

E-mail address: mrm@uevora.pt (M.R. Martins).
}

naturalised in Southern Europe, including Portugal, as an ornamental plant (Bailey and Bailey, 1976; Taylor, 2005). In traditional cuisine, Schinus molle fruits (berries) have been used as a replacement for black pepper and also to prepare alcoholic drinks and beverages (Marongiu et al., 2004). In folk medicine, Schinus molle has been used due to its antibacterial, antiviral, topical antiseptic, antifungal, antioxidant, anti-inflammatory, anti-tumoural, antispasmodic, analgesic properties, as well as a stimulant and an antidepressant (Duke, 1985; Alanís-Garza et al., 2007; Machado et al., 2007; Molina-Salinas et al., 2007; Guala et al., 2009). It has also been used in the treatment of toothache, rheumatism, menstrual disorders, and respiratory and urinary tract infection (Perez and Anesini, 1994; Barrachina et al., 1997; Bello et al., 1998; Marzouk et al., 2006; Atti dos Santos et al., 2010).

The results of some studies have revealed the antimicrobial and antioxidant properties of EOs and extracts of Schinus molle (Dikshit et al., 1986; Hayouni et al., 2008; Murray et al., 2009; SalazarAranda et al., 2011). Phytotoxic and insect repellent actions were reported in studies using ethanolic, petroleum ether and hexanic 